ISSN: 1641-4713; e-ISSN: 2081-1160

DOI: https://doi.org/10.36551/2081-1160.2020.26.221-244

\title{
Cada jurema é uma jurema: Continuidade, rupturas e inovações em religiosidades no Brasil
}

\author{
Each jurema is a jurema: Continuity, ruptures and innovations \\ in religiosities in Brazil
}

\author{
Rodrigo de Azeredo Grünewald \\ Universidade Federal de Campina Grande, Brasil \\ ORCID iD: http://orcid.org/0000-0002-0116-8118 \\ E-mail: grunewald.ufcg@gmail.com \\ Robson Savoldi \\ Universidade Federal de Pernambuco, Brasil \\ ORCID iD: https://orcid.org/0000-0002-4031-4288 \\ E-mail: rjspes@yahoo.com.br
}

Recepción: 29.04.2020

Aprobación: 7.01.2021

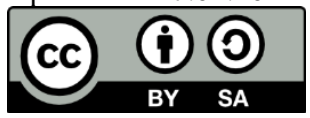

Resumo: No Brasil, algumas plantas, bebidas e religiosidades são chamadas de jurema. Desde o período colonial, se registra o uso ritual da jurema entre indígenas do Nordeste do Brasil. Além disso, a jurema emerge com novas feições em uma religiosidade chamada catimbó, encadeada a partir daqueles ritos, e a qual foi alcançada pela umbanda em meados do século XX. A umbanda se reatualizou em contato com o catimbó, o qual garantiu um lugar para os juremeiros no seu interior ao ponto de encontrarmos na região uma religiosidade conhecida e praticada simplesmente como jurema. Em tais contextos, os fenômenos místicos são considerados relativos a forças misteriosas e elementos encantados. Contudo, cientes de que a jurema contém grande quantidade do alcaloide DMT, psiconautas no exterior do Brasil usaram esta planta misturada com outra oriunda do Oriente para elaborar uma bebida capaz de produzir significativos efeitos psicoativos. Chamada de juremahuasca, essa bebida passou a ser ritualizada no Brasil, onde ganhou contornos de religiosidades, inclusive institucionalizadas. Este artigo evoca essas correntes religiosas, sinalizando suas continuidades, rupturas e reformulações, mas focando mais enfaticamente na juremahuasca que faz parte religiosidades psiconáuticas enteogênicas próprias ao contexto de um misticismo alternativo no Brasil.

Palavras-chave: jurema, religiosidades, juremahuasca, enteógeno, Brasil. 


\begin{abstract}
In Brazil, some plants, drinks and religiosities are called jurema. Since the colonial period, the ritual use of jurema has been recorded among indigenous people in Northeastern Brazil. In addition, the jurema emerges with new features in a religiosity called catimbó, linked to those rites, and which was reached by umbanda in the middle of the 20th century. The latter was reupdated in contact with the catimbó, which guaranteed a place for juremeiros in the interior to the point of finding in the region a religiosity known and practiced simply as jurema. In such contexts, mystical phenomena are considered to be related to mysterious forces and enchanted elements. However, aware that the jurema contains a large quantity of the alkaloid DMT, psychonauts outside Brazil used this plant mixed with another one, originating from the East, to produce a drink capable of producing significant psychoactive effects. Called juremahuasca, this drink started to be ritualized in Brazil, where it became part of religiosities, including institutionalized ones. This article evokes these religious currents, indicating their continuities, ruptures and reformulations, but focusing more emphatically on the juremahuasca that is part of entheogenic psychonautical religiosities proper to the context of an alternative mysticism in Brazil.
\end{abstract}

Keywords: jurema, religiosities, juremahuasca, entheogen, Brazil.

\title{
1. INTRODUÇÃO
}

A jurema é reconhecida como planta sagrada, repleta de poderes e mistérios, por vários sujeitos sociais e místicos em diversos contextos espirituais no Brasil. Registra-se o seu uso desde a época colonial ${ }^{1}$ até a atualidade, confluindo um sistema aberto de trilhas espirituais (Grünewald, 2018) compartilhadas em rituais, quer institucionalizados ou não enquanto religiões.

Suas referências clássicas de uso nativo no Brasil remetem-nos aos grupos indígenas da região Nordeste, cada qual com suas singularidades míticas, místicas e rituais. Além disso, algumas religiosidades - hoje pensadas como tradicionais - também emergiram neste país/região associadas à jurema, como o catimbó, a umbanda, o xangô ou candomblé de caboclo e a recente Jurema Sagrada. Há que se considerar ainda - e de forma bastante enfática para as finalidades deste artigo - reinvenções religiosas da jurema baseadas em espiritualidades holísticas ensejadas pela moderna globalização.

Oriunda dos juremais ${ }^{2}$ do semiárido nordestino, a jurema percorreu trilhas abertas por aventureiros espirituais em múltiplas formas de preparo entre os povos e comunidades tradicionais brasileiras (Grünewald, 2005a) ${ }^{3}$. Existem várias árvores chamadas jurema ${ }^{4}$. Aqui destacamos a jurema preta (Mimosa tenuiflora Willd. Poir.), planta nativa do semiárido nordestino da qual se preparam

\footnotetext{
${ }^{1}$ Para uma revisão exaustiva dessas referências de usos da jurema e rituais a ela associados por indígenas do interior e do litoral do Nordeste, ver Grünewald (2020).

${ }^{2}$ Aglomerado de árvores de jurema.

${ }^{3} \mathrm{E}$ também entre psiconautas promotores de trabalhos espirituais conectados a enteogenia (Grünewald \& Savoldi, 2019), como veremos na próxima seção.

${ }^{4}$ Ver U. P. Albuquerque (2002).
} 
diversas beberagens que se caracterizam por facilitar ou promover experiências místicas. As entrecascas das raízes dessa jurema possuem alto teor do alcaloide N,N-Dimetiltriptamina (DMT), molécula também produzida pelo organismo humano que se relaciona a experiências chamadas místicas e espirituais (Barker et al., 2012). Visto a inatividade oral da DMT (McKenna et al., 1984), já se buscou - a partir do pressuposto da riqueza do saber botânico indígena em sua capacidade de combinação e experimentação de diferentes plantas - por um suposto "segredo da jurema", quando se indagavam alguns pesquisadores, como, por exemplo, Grünewald (2002), sobre qual planta (ou outro elemento da natureza, como algum mel etc.) se misturaria a ela de forma a ser psicoativa para os indígenas. Não se chegou até hoje a nenhuma conclusão, embora misturas de diferentes elementos com a jurema tenham sido relatadas.

Contudo, em uma conjuntura internacional de fins da década de 1990, um viés experimentalista impulsionou uma nova mistura com psicoativos, quando a planta jurema (Mimosa tenuiflora Willd. Poir.) foi associada a sementes da planta arruda da Síria (Peganum harmala L.) - esta nativa da Ásia Central, Norte da África e Oriente Médio. Dessa composição foi originada a bebida chamada de juremahuasca, uma "jurema transmutada" que passou a ser consumida ritualmente em diversos países e por vários experimentadores, que, em sua maioria passaram a ser considerados como psiconautas, isto é, viajantes da alma ou da mente (Jünger, 1970). De fato, além dos modos místicos e religiosos tradicionais, essa jurema transnacional, quando territorializada no Brasil, se reconfigurou em uma espiritualidade e religiosidades próprias a um "misticismo alternativo" (Soares, 1994) então em voga nesse país. Seus diferentes usos e contextos convivem entre si, muitas vezes nas mesmas pessoas, como demonstrado pioneiramente por M. A. de S. Albuquerque (2002) a partir de elementos empíricos aos quais se somaram vários exemplos posteriores, como alguns apresentados mais recentemente por Grünewald e Savoldi (2019).

Segundo Bairrão (2003), a representação social da jurema revela um conjunto de significados - o "campo semântico da jurema", como estabeleceu Grünewald (2020) -, muitas vezes entrelaçados e até intercambiáveis entre si: jurema pode ser planta, bebida, cerimônia religiosa, entidade, mundo ou plano espiritual, índia metafísica, linhas de trabalhos espirituais, nome próprio, entre outras coisas. Pelo exposto, nos é difícil aplicar um conceito canônico de religião às espiritualidades que têm na jurema seu elemento essencial - mesmo que essas sejam chamadas, por grupos de sujeitos adeptos dos ritos a ela associados, de "religião" (Grünewald, 2018). No entanto, podemos nos referir a processos históricos diferentes nas inovações culturais e sociais que cercam o fenômeno social e religioso da jurema no Brasil. 
Retomamos nas seções abaixo parte do universo religioso das juremas, avançando mais densamente sobre experimentalismos psiconáuticos e religiosidades brasileiras e eles vinculadas. Através de revisão bibliográfica, observações empíricas e depoimentos de pessoas de diversas religiosidades, argumentamos que a jurema se dispõe como força espiritual fundamental, tanto por conter em sua composição química o alcaloide N,N,-Dimetiltriptamina (DMT), mas também sem que isso seja levado em considerações pelos usuários em vários contextos tradicionais nos quais a bebida ingerida não permite a ação desse alcaloide. Com uma função informativa sobre as religiosidades atuais da jurema, elementos teóricos específicos aos diversos contextos de uso da jurema são informados e discutidos nas próprias seções onde tais contextos são apresentados.

\section{AS PRIMEIRAS TRADIÇÕES DA JUREMA}

Não há registros arqueológicos que nos informem sobre o uso da jurema em tempos pré-coloniais. Só com a perseguição aos cultos de jurema pela inquisição portuguesa à época colonial que nos chegam algumas informações (Grünewald 2020; Wadsworth, 2006). Nesse sentido, o primeiro registro bem estruturado de um ritual com jurema foi realizado em 1938 na festa do Ajucá, entre os Pankararu, em Pernambuco (de Oliveira, 1942). Na mesma época, a Missão de Pesquisas Folclóricas organizada por Mario de Andrade na década de 1930 buscou inventariar aquilo que denominava "manifestações culturais brasileiras" (Carlini, 1993), inclusive em 1938 entre os Pankararu, que tiveram seu toré (e outras performances) registrado. Já o químico pernambucano Gonçalves de Lima (1944) retorna aos Pankararu de Tacaratu em 1942, quando encontrou o DMT (inicialmente chamada Nigerina) na jurema preta.

Daí em diante, a dança cerimonial do toré e o uso da jurema muitas vezes a ela associada passam a ser constantes na etnologia dos índios do interior do Nordeste (Hohenthal, 1960; Pinto, 1956) e, muitas vezes, esmiuçadas em relatos, ou em etnografias mais recentes desenvolvidas a partir de fins da década de 1980 (Batista, 1992; da Mota, 1987; Grünewald, 1993; Mata, 1989; Nascimento, 1994).

Adiantamos que é nos rituais mais discretos que a jurema ganha maior centralidade como uma bebida sacramental, ou enteógeno - termo cunhado por Ruck et al. (1979) e que se refere ao advento de Deus na pessoa. De fato, ressaltamos aqui uma dimensão pública do toré (geralmente ritos festivos e políticos, muitas vezes sem consumo de jurema) e outra privada (na maioria das vezes com consumo de jurema) para fins variados (geralmente cura) e que são recorrentes 
a praticamente todos os povos indígenas do Nordeste do Brasil, sendo que cada um deles desenvolveu sua maneira específica de elaboração ritual e de lidar com a jurema (Grünewald, 2018). Vale lembrar que o ritual do toré e os usos da jurema foram elementos difundidos vigorosamente entre os índios do Nordeste a partir da década de 1930 e que perdura até os dias atuais, sendo fundamental em muitas etnogêneses, sendo marca de indianidade geral dos índios dessa região do Brasil. Tal perspectiva se baseava no princípio das perdas culturais nativas e da assimilação de elementos culturais e raciais (inclusive ressaltando a miscigenação com indivíduos negros) da sociedade brasileira regional, de modo que, por décadas, fizeram parte dos remanescentes indígenas conhecidos na etnologia como "índios misturados" (Pacheco de Oliveira, 1999).

O toré, portanto, se refere particularmente a uma tradição indígena nordestina na qual uma ostentação distintiva e bastante lúdica da etnicidade é observada. Já a jurema ganha maior centralidade nos rituais fechados das chamadas mesas, que operam com grande circunspecção e quando segredos e mistérios se destacam para as finalidades de cura (principalmente), mas de aconselhamentos etc. para consulentes e outras pessoas especialistas rituais que ajudam o mestre na condução ritual. Ambas as esferas rituais (o toré e a mesa de jurema) são peças importantes para o regime de índio (Grünewald, 1993, 2001, 2005b) desses grupos, que por meio delas, atualizam suas tradições performáticas e esotéricas mantendo viva e sacralizada suas identidades étnicas.

Além do toré, o ouricuri é também uma ampla instância ritual (especialmente entre Fulni-ô e Kariri-Xocó, mas presente também entre outros grupos) importante enquanto forma de retiro espiritual indígena, quando se propõem a rememorar suas cosmologias e concepção da indianidade, reconstituindo o laço essencial com sua ancestralidade. Por fim, em diferentes grupos, e em circunstâncias específicas, a jurema (ou "vinho da jurema") pode receber outros nomes, como ajucá, anjucá ou cotcha-lá.

Não devemos esquecer que muitos indígenas (e grupos de índios) do interior do Nordeste foram, por diversos motivos, habitar a região litorânea e suas proximidades. Misturaram-se aos índios locais, mas também à população branca, mestiça e negra rural em geral (mas também urbana), como também se acomodaram em quilombos, misturando-se à população negra mais aguerrida. Sabemos também que os indígenas do interior e do litoral tiveram contatos os mais variados e que outros elementos étnicos a eles se associaram fazendo com que suas religiosidades se entrecruzassem. De fato, como apontou Sangirardi (1983), “os pajés indígenas ensinaram aos brancos e mestiços os mistérios da pajelança. Esta in- 
fluiu no catimbó. Uma e outra receberam a mescla do espiritismo, da feitiçaria europeia e, nas orações e imagens dos santos, do catolicismo. Depois de completado o ciclo, o pajé indígena recebe de volta, sincretizado, tudo aquilo que ensinara. E passa, inclusive, a trabalhar com os encantados" próprios ao catimbó (Sangirardi, 1983, p. 194).

Muito provavelmente, os saberes em torno da jurema nativa do interior seguiram com os indígenas, mas também pessoas e grupos do litoral foram ao interior (como escravos, trabalhadores etc.) e depois voltaram à região litorânea. Muitos desses foram inclusive acolhidos por índios do sertão se misturando com eles. O trânsito entre os elementos étnicos e religiosos no Nordeste são caminhos ainda pouco estudados ou passíveis de serem determinados com alguma exatidão. A maioria das referências coloniais quanto ao uso da jurema e sua perseguição pela Inquisição portuguesa referem-se a setores nordestinos mais próximos do litoral. E, de fato, o catimbó se espalhou pelas periferias nordestinas desde o Rio Grande do Norte até Alagoas, pelo litoral e especialmente pela Zona da Mata da Paraíba e Pernambuco, mas ainda pelos centros urbanos, indo encontrar, entre outras afro-religiosidades, os xangôs urbanos em Recife, Olinda etc.

Cascudo (1937) via o catimbó como prática mágica, feitiçaria e curandeirismo. Para este autor, ao se referir ao catimbó, não se podia caracterizá-la como religião. Isso, segundo Barros (2011), teria relegado o catimbó a uma "posição inferiorizada no campo das religiosidades afro-brasileiras" (Barros, 2011, p. 72). De qualquer forma, jurema é a referência que se firma em torno do catimbó, o qual ainda era considerado feitiçaria na década de 1950 - como reafirmava veementemente Cascudo em Meleagro (1978). Na década de 1970, em sua pesquisa de campo na região de Alhandra, no litoral da Paraíba, Vandezande (1975) notava que os catimbozeiros eram localmente conhecidos como "juremeiros" (Vandezande, 1975, p. 128). As cidades da jurema já foram descritas desde a década de 1930 por autores como: Cascudo (1937; 1978), Fernandes (1938), Bastide (1945) entre outros. A Missão de Pesquisas Folclóricas coordenada por Mario de Andrade em 1938 (Carlini, 1993) também registrou aspectos culturais do catimbó da região. Em função das considerações desses autores, o termo catimbó ficou muito atrelado à ideia de feitiçaria e era considerada (Bastide, 1945) uma religiosidade (do "baixo espiritismo") uma religiosidade mais precária do que o candomblé, com poucos elementos autênticos e visando mais especificamente curas e aconselhamentos individuais dados pelos mestres que ali incorporavam para essas finalidades. Esses mestres, que já haviam passado por vida em matéria, habitavam as cidades (e Estados e reinos). $\mathrm{O}$ uso da jurema era funda- 
mental nessa religiosidade. As mesas se compunham também dos cachimbos (que era outro elemento essencial para comunicação com os mestres), cachaça, velas, bacias e taças (chamadas de príncipes e princesas) etc. Sua forma ritual guarda semelhanças com as mesas dos indígenas. Há que se notar, por fim, que tanto entre os indígenas quanto entre os catimbozeiros, nunca houve uma institucionalização das religiosidades juremeiras, ou seja, uma formalização enquanto religião ou igrejas.

Como já sinalizamos, dentro de uma mesma aldeia indígena há rituais conduzidos diferentemente, pois vários dos seus dirigentes (detentores da ciência do índio ${ }^{5}$ ) podem trabalhar com correntes distintas. Por exemplo, os relatos de de Oliveira (1942), Batista (1992), Grünewald (1993; 2002) ou C. B. Silva (2000) mostram como há muita similaridade morfológica e fisiológica dos rituais de mesas, com suas cruzes, aribés de jurema e cuias com a "cura", cachimbos, velas, santos, cânticos, mestres e encantados etc., e de como esses se assemelham às mesas do catimbó (mas essas já não mais dispostas no chão, como as indígenas).

Com relação especificamente à região de Alhandra $(\mathrm{PB})$, a umbanda vai encontrar o catimbó ali existente, o qual lhe entregará um importante "legado mítico e simbólico, advindo da tradição local dos mestres juremeiros" (de Salles, 2004, p. 101). Mas, se foi Vandezande (1975) quem situou Alhandra como o local de surgimento de uma nova religiosidade então conhecida como catimbó, foi ele também quem primeiro mostrou seu processo de umbandização. Em sua aproximação ao Nordeste, a umbanda forneceu um espaço para que as práticas próprias ao catimbó se desenvolvessem também no seu interior. Segundo de Salles (2004), "por meio da disciplina e padronização dos ritos, organizar a religião, exercendo um controle sobre sua prática através de canais oficiais. A partir da década de 1950, irão surgir federações de Umbanda em vários Estados do país. Estas irão desempenhar um papel fundamental na expansão desta religião em âmbito nacional" (de Salles, 2004, p. 113). Em 1966 foi aprovada a Lei $n^{\circ} 3.443$, que garantia liberdade de culto em todo o estado da Paraíba e criava a Federação dos Cultos Africanos do Estado da Paraíba, à qual os terreiros teriam que estar filiados. Tal Federação tinha, entre outras, a atribuição formal de disciplinar o exercício desses cultos (de Salles, 2004).

Mas, segundo depoimentos diversos, o culto da jurema próprio ao catimbó começou a perder suas características à medida que a umbanda estendia seu domínio na região. Os juremeiros tiveram que se associar formalmente

\footnotetext{
${ }^{5}$ Corpo de saberes sagrados e dinâmicos sobre o qual se fundamenta os mistérios do grupo étnico (Grünewald, 2005a).
} 
à umbanda e incorporar práticas rituais desta religiosidade, a qual, por sua vez, incluiu em seu panteão uma figura sagrada da jurema metamorfoseada num arquétipo indígena feminino a ser venerada entre seus caboclos. Mas, se o catimbó incorporou elementos da umbanda, não deixou, entretanto, de praticar uma tradição de jurema, que ganharia lugar distinto entre os orixás e demais entidades da umbanda. Inclusive, em diversos lugares desde o Rio Grande do Norte até Alagoas, "o culto à jurema é considerado a porta de entrada para a iniciação religiosa dos adeptos. É tanto que, nos processos iniciatórios, os neófitos primeiro passam pelos rituais da jurema para, em seguida, serem inseridos nos preceitos do orixá" (Santiago, 2008, p. 4).

Assim, além dos catimbós que ainda se praticam em casas pequenas, dentro das casas de umbanda (ou de "jurema") se resguardam espaços para se trabalhar - quer trabalhando na ciência pelo pensamento (trabalho mental), quer por meio da manifestação mediúnica - com os mestres próprios à jurema, que são chamados das suas cidades. Este é o caso da jurema arriada, ou jurema de chão; ritual realizado em muitas das casas de umbanda da região Nordeste e no qual os adeptos sentam-se em banquinhos e com seus maracás e cachimbos chamam os mestres de suas cidades para se fazer presentes na sessão a partir da ciência dos pontos riscados e outros elementos.

Mas isso não quer dizer que essas casas sigam a um mesmo padrão sem variações particulares. Brandão e Rios (2001) indicam, por exemplo, a existência uma grande diversidade de juremas (casas religiosas assim chamadas) nas periferias de Recife. Como afirmam, jurema não é algo institucionalizado que segue leis severas. Oriunda dos mestres catimbozeiros, essas casas são chamadas a partir da referência ao seu dirigente (por exemplo: a jurema de Maria; a jurema de José etc.), cada qual com a liberdade de renovar tradições e inovar em vários aspectos. Apesar dessa diversidade, essas casas de culto remeteriam às antigas características do catimbó, como as cidades, os reinos e outros elementos.

Motta (1985), por sua vez, elege o xangô como a principal expressão religiosa afro-brasileira de Pernambuco e com ocorrência tanto na capital (zona urbana em geral) quanto na Zona da Mata. Em tal religiosidade, elementos ameríndios estão presentes, sendo fundamental, como no catimbó, o uso do tabaco e da jurema para celebração tanto das entidades encantadas, como espíritos indígenas e africanos. Se o xangô assim se apresenta compartilhando elementos também essenciais à jurema de umbanda, fica difícil separar e classificar drástica e de forma estanque as fronteiras dessas religiosidades. A jurema umbandizada também se espalha pela mesma ampla região, se fazendo presente, por exemplo, nos 
folguedos pernambucanos como o Cavalo-Marinho, os Caboclinhos, a Caçada do Bode, no Maracatu Nação e no Rural.

Contudo, a umbanda é uma religião mais propriamente urbana e, nesses espaços, não mais as árvores de jurema, mas partes dos seus troncos, as tronqueiras, passaram a serem colocadas em espaços especiais, geralmente pejis, onde são consagradas como se fossem a planta viva. É assim que "hoje, sob a influência da umbanda em todo campo religioso juremeiro, as Cidades da Jurema, como morada dos mestres, passam a ser representadas pelos pejís de Jurema, onde são colocadas as tronqueiras" (Lima Segundo, 2015, p. 72).

Por fim, um segmento religioso que vem se desenvolvendo nessa região ficou conhecido como Jurema Sagrada. Esta busca introduzir uma possível "teologia da Jurema Sagrada, religião tida pelos juremeiros e juremeiras como a 'religião primaz do Brasil' e também como de 'matriz indígena', sobretudo etnicamente tupi, em suas diversas etnias, pertencente a grande parte do Nordeste brasileiro, principalmente a Alagoas, Pernambuco, Paraíba, Rio Grande do Norte e Ceará" (Oliveira (L'Omi L'Odò), 2011, p. 1083). Segundo ele, não existe ainda uma teologia escrita e codificada sobre o culto da Jurema Sagrada embora os juremeiros afirmem que a Jurema é a religião mais forte historicamente, por sua força de sobrevivência aos processos de atrofiamento teológico, cultural e histórico. Ainda acreditam ser possível um resgate do imaginário mais antigo das práticas indígenas para fortalecer as práticas hoje umbandizadas (L'Odò, 2017).

Santos (2007), por sua vez, destaca a Jurema Sagrada como "uma prática xamã, de tradição oral, que seus próprios praticantes não têm certeza de sua origem" (Santos, 2007, p. 9). Jurema para ele é um "conhecimento" realizado a partir de elementos da natureza e, embora seus adeptos a tenham como "religião", para ele tratase de "um conhecimento e um aprendizado de como lidar com determinadas possibilidades da natureza. Uma ciência, portanto, e não uma religião. Tanto que é muito comum juremeiros frequentarem igrejas católicas, terreiros de candomblé, de umbanda ou outra religião, não havendo conflito algum entre as diversas práticas.

Alexandre L'Omi L'Odò, idealizou o Kipupa Malunguinho (levado adiante junto ao Quilombo Cultural Malunguinho desde 2006), evento que ocorre na municipalidade de Abreu e Lima, na Zona da Mata pernambucana, em terras onde se situava o antigo Quilombo do Catucá, liderado por Malunguinho. Ali se fazem rituais em matas fechadas e dançam-se os cocos, que "é o ritmo que os mestres dançam". Para lá anualmente acorrem uma variedade de juremeiros nordestinos, que chegam em muitos ônibus e outros veículos, que sabem "preparar fumo com jurema, cachimbo com jurema" e as "duas bebidas da jurema": a de salão, que 
é aquela beberagem que mistura as ervas tudinho e podendo ou não conter partes da planta jurema; e a de consagração que é a feita com a entrecasca da jurema. Esta última já teria seu conhecimento sido perdido por muitas pessoas, mas parece que está sendo resgatado para se fortalecer uma original "prática transcendental com o uso da bebida".

L'Odò (2017) afirma que, na cosmovisão da jurema sagrada, essa "religião" prescinde dos "efeitos químicos da jurema para ter contato com a espiritualidade". Não é relevante se as partes da planta utilizadas nos preparos rituais contêm ou não o DMT: ela é para limpar, purificar, chamar forças, intuitos terapêuticos etc. Sobre esses usos, eles são cercados por mistérios e segredos, envolvendo inclusive outras árvores ou plantas essenciais para sua reprodução cosmológica. Essa ciência dependeria necessariamente da natureza nordestina e esta espiritualidade, portanto, deveria estar restrita a essa região do Brasil.

Embora a molécula de DMT não seja conhecida pela maioria desses juremeiros tradicionais - e que não seja um cálculo que entre na perspectiva mística acionada por eles (mesmo os que conhecem as potencialidades do DMT) -, é curioso essa retomada acerca da importância da bebida jurema ser necessariamente feita das entrecascas das raízes da planta (como fazem os índios e antigos catimbozeiros). Não só pela afirmação política de uma religiosidade que esteve muitos anos subordinada a um lugar menor dentro das grandes casas religiosas afro-brasileiras do Nordeste, mas por seu caráter "transcendental". E é assim, a partir desse viés, que passamos agora para uma apresentação da jurema enteogênica própria de um psiconautismo religioso no Brasil.

\section{JUREMAHUASCA: A BUSCA DA DIVINDADE INTERIOR POR SUJEITOS PÓS-MODERNOS}

Dentre suas múltiplas faces, a jurema foi ressignificada diasporicamente e realocada a partir da agência de novos sujeitos, que, por não se apegarem a identidades religiosas fixas e em sua fluidez esotérica e navegação exotérica, foram já chamados de "pós-modernos" (Grünewald, 2008, 2018). Por causa das suas altas concentrações de DMT ela foi reinventada, transmutada e se reconfigurou em novos trabalhos espirituais (M. A. de S. Albuquerque, 2002; da Mota, 2005; Grünewald, 2002, 2005a, 2008, 2018, 2020; Grünewald \& Savoldi, 2019) A década de 1990 reacendeu os estudos com DMT e foram publicados trabalhos científicos sobre a "molécula do espírito" e seus efeitos fisiológicos, psicológicos e espirituais (Strassman, 1996; Strassman et al., 1994). 
A jurema não passou por uma experimentação mais abrangente, como a iniciada pela contracultura psicodélica que incluía ayahuasca, peyote e cogumelos que estimulou o turismo enteogênico. Já se destacou na literatura (Grünewald, 2002, 2005a, 2008) como uma nova forma de elaborar uma bebida jurema foi criada como uma análoga da ayahuasca - uma anahuasca, segundo seu criador Jonathan Ott (2002) -, que acabou ficando mais propriamente categorizada de juremahuasca (Labate, 2000).

O termo psiconauta foi inaugurado por Enst Jünger na década de 1970 e significa literalmente viajante da alma ou mente. Pode se referir tanto à metodologia para descrever e explorar efeitos subjetivos de estados alterados de consciência, quanto ao paradigma de pesquisa de bioensaios, em que o estudioso mergulha em seu interior - no Psicocosmo, de acordo com Jünger - através de psicofármacos (Newcombe \& Johnson, 1999). Ao se utilizarem de técnicas para navegar pela mente - como hipnose, privação sensorial, ondas cerebrais, meditação, uso de psicodélicos, sonhos lúcidos -, os psiconautas são buscadores que investigam sua psique através de estados alterados de consciência induzidos intencionalmente para propósitos espirituais, científicos ou de pesquisa e autoconhecimento (Bloom, 2009).

Enquanto a jurema da qual foram preparadas as primeiras juremahuascas tinha origem no México (e, em seguida, no Brasil), a fonte da substância que prontamente habilitava os efeitos da jurema de forma eficaz, o $\mathrm{IMAO}^{6}$, veio de sementes da arruda da Síria (Peganum harmala L.), conseguidas na Europa e Norte da África. Planta exclusiva de seu gênero, da qual foi extraída a harmalina (Carreras \& Alonso, 1967), a arruda da Síria é uma planta considerada de mistérios e poderes no Oriente, onde é endêmica. E, justamente por suas altas concentração de alcaloides inibidores da MAO, deve-se a escolha de suas sementes para a preparação das anahuascas ${ }^{7}$ (Ott, 2011).

É possível encontrar websites e fóruns na internet (principalmente não brasileiros) que discorrem sobre os usos psiconáuticos de uma infinidade de substâncias, farmacologia, efeitos, segurança no uso, enteogenia em geral e experiências. Um desses sites internacionais é apresentado como uma "wikipédia psiconáutica" e contém relatos e receitas com jurema. Apesar de nomearem de "ayahuasca", grande parte dos relatos de experiência se refere a receitas de jurema

\footnotetext{
${ }^{6}$ O DMT não é ativo oralmente uma vez que a monoamixidase (MAO), enzima do trato gastrointestinal, não permite sua absorção. Assim, faz-se necessário o uso concomitante com inibidores da monoamixidase (IMAO) para que o DMT seja absorvido na ingestão produzindo os efeitos psicotrópicos (Mckenna et al., 1984).

${ }^{7}$ Uma denominação complementar são as farmahuascas (Ott, 2002), quando pelo menos um dos dois principais componentes do análogo são as moléculas puras ou quase puras, em dosagens específicas.
} 
com arruda da Síria e não propriamente a ayahuasca (feita de folhas de Psychotria viridis e cipó Banisteriopsis caapi). Entre essas receitas incluem-se vitamina (ayahuasca smoothies), bolo (ayahuasca cupcakes), bebida (ayahuasca brew) e sanduíche (ayahuasca sandwich) preparados com jurema e consumidos após 20-60 minutos de uma dose de arruda da Síria. Segundo informações deste website, os psiconautas se diferenciam dos usuários recreativos de drogas em termos de objetivos e métodos: o psiconautismo está relacionado à pesquisa e principalmente para fins espirituais e estudos da natureza da consciência. Apesar desse contraste, o uso recreativo procurado para fins de prazer e diversão pode, por vezes, aparecer como subproduto do uso psiconáutico. Nesse sentido, é importante lembrar que a distinção entre os dois contextos depende inteiramente da intenção principal do sujeito ${ }^{8}$.

De fato, se os psiconautas europeus são experts nos efeitos fisiológicos e bioquímicos da jurema, os brasileiros, mesmo sabendo do assunto, o relegaram, de uma maneira geral, ao plano específico dos cientistas modernos e, achando-se talvez mais que modernos, preferiram manter-se atentos aos ensinamentos que poderiam vir dos planos misteriosos/sagrados. As plantas rituais podem apresentar importante função mediadora entre os planos de existência terrena (representações físicas) e espiritual (representações cosmológicas ou sobrenaturais) que, através de ritos, lhes conferem "valor sacral" (Camargo, 2014). E, de fato, esses juremeiros brasileiros pós-modernos buscam trazer "vozes nativas as mais diversas para atuarem como sujeitos com conhecimentos tão importantes e legítimos quanto os porta-vozes das grandes tradições religiosas, filosóficas e científicas" (Grünewald, 2018, p. 126). Por sua vez, promoveram a aura de religião - ou, pelo menos, de religiosidade - a essas práticas rituais, que, enfim, convergiram para um "psiconautismo religioso da jurema" (Grünewald \& Savoldi, 2019). Com a juremahuasca, um elemento importante no surgimento da sua espiritualidade foi o fato de oferecer uma alternativa às religiões em geral e às religiosidades ayahuasqueiras institucionalizadas no Brasil.

No mundo pós-moderno contemporâneo, apesar da força de fundamentalismos que avançam contundentemente, percebemos novos sujeitos espiritualistas que, não procuram mais impor de forma absoluta suas perspectivas religiosas, mas estabelecer um diálogo transcultural como base reflexiva "macroecumênica" na medida em que uma "nova consciência religiosa" (Soares, 1994) deve

\footnotetext{
${ }^{8}$ Ver https://psychonautwiki.org.

${ }^{9}$ Emprestamo-nos termo usado pelos criadores do Encontro da Nova Consciência, evento que ocorre durante os carnavais na cidade de Campina Grande (PB) e que ficou conhecido como Almaval e o qual já foi descrito por Amaral (2000).
} 
atentar para um tipo de relação com a religiosidade com destaque para a pluralidade (incluindo a enteogênica), pelo trânsito interreligioso e para a dúvida (incluindo também a enteogênica), pela constante reflexão sobre as variadas experiências em exposição.

Constatamos uma diversidade de elementos estruturais e performáticos nos rituais de grupos que, no Brasil, já utilizaram ou que utilizam atualmente a juremahuasca - embora muito de suas bricolagens tenha por base elementos de tradições religiosas, esotéricas ou filosóficas comuns. Podemos, esquematicamente, distinguir dois momentos mais intensos desses usos rituais.

Os primeiros sujeitos da juremahuasca no Brasil foram minuciosamente descritos inicialmente por M. A. de S. Albuquerque (2002). Os primeiros desses juremeiros iniciaram suas configurações rituais no início de 1997 (Grünewald, 2005a, 2020) e seus trabalhos regulares perduraram até 2005 e outros antes disso. Temos notícias de seis grupos rituais somente que atuaram, cada qual a sua maneira, nos estados de Goiás, Rio de Janeiro, Paraíba e Santa Catarina. Um desses grupos foi institucionalizado como religião, com a criação, em 2002, do Centro de Comunhão Enteogênica Flor de Jurema, o qual funcionou por poucos anos em Piabetá (RJ).

Todos esses grupos se orientavam por uma noção de comunhão divina e se voltavam também para uma perspectiva de cura. Havia uma ligação especial com as religiosidades ayahuasqueiras, visto que muitos desses juremeiros eram a elas ligados (institucionalmente ou não) em termos de práticas rituais. Alguns deles eram permissivos com a utilização de ambas as bebidas (jurema e ayahuasca ${ }^{10}$ ) nos mesmos rituais e outros separavam totalmente essas bebidas e rituais demarcando fortemente o espaço para cada uma. Uns apresentavam propostas terapêuticas formais e outros não se referiam a isso. Havia trabalhos fechados ou abertos ao público, cada qual apresentando características próprias, pois tais sujeitos ajustavam criativamente em seus trabalhos elementos oriundos de elementos musicais dos indígenas nordestinos (um deles fazia trabalhos completos como o dos índios Atikum e Kapinawá - só que, em boa parte das vezes, sentados e não dançando como nos torés -, incluindo aberturas, encerramentos e outras facetas), da umbanda, música popular brasileira (especialmente as de caráter espiritualizado), mas também músicas instrumentais típicas da Nova Era, música xamânica, música étnica do mundo todo - com ênfase nas do mundo árabe, do hinduísmo e do budismo -, e alguns incluíam ainda manifestações artísticas diversas (desde desenhos até coreografias etc.), bem como dinâmicas ecológicas ou práticas próprias de retiros espirituais, como dias de silêncio etc. Esses trabalhos aconteciam com

\footnotetext{
${ }^{10} \mathrm{E}$, às vezes, até outras, como maconha (Cannabis sativa), San Pedro ou Wachuma (Trichocereus pachanoi), trombeta (Brugmansia suaveolens) etc. (M. A. de S. Albuquerque, 2002).
} 
regularidade variável, podendo ser semanais, quinzenais ou mais esporádicos. Somente um desses dirigentes rituais colhia a jurema pessoalmente em matas paraibanas. $\mathrm{O}$ restante desses juremeiros tinha que adquiri-la por outros meios. Quanto à arruda, aquele juremeiro que coletava jurema na Paraíba obtinha essa planta exógena vinda do Iran ou do Egito a partir de dádivas de amigos que as traziam em grande quantidade. Já os outros encontravam mais dificuldades para acesso a ela.

Depois desses primeiros grupos que foram parando de proporcionar rituais com a jurema por motivos diversos, por volta de meados da primeira década do século XXI, sabemos de outros trabalhos enteogênicos com jurema que buscaram se estabelecer na Paraíba e Sergipe. Um estrangeiro criou um grupo em João Pessoa com características New Age. Não temos referências às dinâmicas desses trabalhos. Já um dirigente de um ponto do Santo Daime do litoral paraibano que frequentava o trabalho de João Pessoa acabou por iniciar trabalhos (mais informais) com jurema no âmbito daquela igreja, mas também não sabemos como isso se processava e se há continuidade. O trabalho em Sergipe, que seria levado à frente por um daimista, acabou não se consolidando.

Queremos registrar também que, como observado empiricamente por um dos autores, na passagem do século XX para o XXI, alguns grupos de indígenas nordestinos (especialmente Kariri-Xocó e Fulni-ô) começaram a apresentar trabalhos de toré em forma de workshops nas grandes cidades brasileiras, inicialmente sem o uso de jurema. Posteriormente, em função de demanda dos citadinos, formataram rituais com o uso de juremas brancas, já rotuladas de "medicinas da floresta" por essas pessoas da cidade que não tinham a menor noção acerca do modo de vida de tais indígenas e de seus rituais nas aldeias de origem. Esses indígenas, além do legado dos primeiros juremahuasqueiros acima mencionados, talvez tenham influenciado os juremeiros que surgiriam mais recentemente.

De fato, novos sujeitos da juremahuasca que emergiram na última década consideram o legado enteogênico e psiconáutico daqueles primeiros, e seguem alguns rastros deixados em suas trilhas espirituais. Contudo, incorporam em seus trabalhos preocupações mais holísticas e novas receitas e formas de uso da jurema.

Ao relatar uma história mítica que thes foi contada por um pajé KaririXocó, da Mota e Barros (2002) destacam que em tal narrativa o preparo adequado da bebida da jurema é ensinado pela própria planta/entidade. Isso enfatiza o processo disciplinador da planta sagrada: "Entre os Cariri ${ }^{11}$, a Jurema é a divindade criadora que se apresentou, o passado mítico, ensinando a uma das primeiras mulheres a preparar uma "bebida especial"' (da Mota \& Barros, 2002, p. 36).

${ }^{11}$ Cariri foi grafia utilizada no artigo citado em referência ao povo indígena Kariri-Xocó. 
Partindo dessa perspectiva, temos uma continuidade desse aspecto disciplinador, que segundo Grünewald e Savoldi (2019), é comum a todos os neojuremeiros desta segunda geração, os quais afirmam terem desenvolvido:

uma experiência que faz com que se sintam qualificados para dirigir rituais com essa planta/bebida a partir do próprio uso da jurema ${ }^{12}$, bem como de outras plantas e fungos psicoativos. A configuração dos rituais em todos os grupos surgiu através da própria prática desses indivíduos associada a diversas religiosidades. Seus ritos envolvem meditação, esoterismo, canto, dança e vivências xamânicas. Todos fazem trabalhos regulares, mas com frequência variada. Todos trabalham com entidades espirituais, alguns com incorporação e outros não. Entre as finalidades dos ritos encontramos autoconhecimento, contato com seres divinos, integração "ao todo" e à natureza, cura, celebração, arte, magia. Os conhecimentos e a integração entre os saberes místicos e a realidade cotidiana são organizados através do diálogo, conversas e pelo próprio mundo espiritual, além de estudos bibliográficos sobre vários ramos do conhecimento humano. É importante ressaltar a presença do lúdico (durante ou após o ritual) entre os grupos estudados. Nenhum dos dirigentes considera seu ritual recreativo ou puramente prazeroso. Todos, em oposição, sustentam que fazem "trabalhos espirituais", "vivências", "rituais" e "celebrações". (Grünewald e Savoldi, 2019, p. 341)

Por trabalhos, Grünewald e Savoldi (2019, p. 336) designam a relação (e operação) intencional com (e sobre) as forças espirituais. Indo além, são encontrados nesses trabalhos traços essenciais do que é comumente visto como ritual: uma ordenação estruturante (abertura e fechamento etc.); um sentido de realização coletiva com propósito definido; a percepção de que são eventos extraordinários, fora do cotidiano (Tambiah, 2017). Deve-se entender o ritual para além do aspecto convencional como construto cultural, que tem características que o legitimam como tal, já que estão sujeitos a um continuum de transformação que depende do contexto em que as pessoas se encontram (Rodrigues, 2014).

A linguagem ritual tem a mesma essência da linguagem ordinária, ou seja, usa metáforas e outras figuras de linguagem com o objetivo de transferir uma qualidade ao recipiente de modo que mesmo que não se entenda a palavra em si, entendese o rito e a sua função (Peirano, 2000). Os rituais enteogênicos da jurema que são próprios a cada casa se referem a músicas, orações, trabalhos corporais, meditações e podem ser mesclados variadamente com elementos das religiosidades ayahuasqueiras, dos índios do Nordeste, da umbanda, do candomblé, do espiritismo, do xamanismo indígena em geral, do sufismo, hinduísmo, budismo (o Caminho do Meio é uma filosofia lugar-comum na retórica de vários desses atores), yoga, técnicas de respiração, Reiki, danças, pinturas, improvisação musical (Grünewald, 2018).

${ }^{12}$ Queremos atentar para o fato de que essa jurema misturada com arruda da Síria é chamada somente de "jurema" pelos seus buscadores (Grunewald \& Savoldi, 2019). 
Uma das religiosidades de juremahuasca foi institucionalizada em 2014; o Ashram - Centro de Desenvolvimento Espiritual Morada de Shiva. Essa casa religiosa promove rituais meditativos com várias composições a partir das experiências do dirigente no Tibete, Índia, China, Tailândia e Japão, inclusão de técnicas psicoterapêuticas como dinâmicas de grupo, terapias corporais, Rolfing, Rebirthing, Respiração Holotrópica, Gestalt Terapia, Taichi, yoga induísmo, budismo e taoísmo; tambem lança mão de percussão com tambores e até cantos e danças, quando há convidados indígenas, com os quais aprendeu e foi considerado xamã branco (pelos Fulni-ôs e Kariri-Xocós). Além de usar jurema com arruda da Síria por vezes também há mistura em seus "rituais xamânicos" com outros elementos que podem atuar como IMAO, como a ayahuasca ("com pouca folha e muito cipó") ou a erva de São João - ou hipérico (Hipericum perforatum L.) ${ }^{13}$, assim como também alterna enteógenos ou se recozinha uns com outros. Não há objetivo comercial ou de adepto de seguidores, sendo rituais para convidados que rateiam os custos das despesas básicas (Grünewald \& Savoldi, 2019).

Com base nos conhecimentos da ayahuasca e DMT, surgiu também no Brasil, mais especificamente em 2018 no estado do Ceará, a primeira Igreja que toma como sacramento a molécula do espírito e inclusive possui livro sagrado de 238 versos que delineiam a estrutura operacional dos ritos. Regulamentada por lei, a Igreja do Divino Mestre na Terra (acrônimo de IDMT), propõe tanto o desenvolvimento espiritual e religioso a partir da DMT - tanto a jurema bebida quanto fumada em formato de changa ${ }^{14}$ - e outros enteógenos atrelados a uma lógica científica moderna, terapêutica e de redução de dano $\mathrm{s}^{15} \mathrm{em}$ rituais próprios, considerando set e setting ${ }^{16}$ com a retorica do psiconautismo enteogênico, tendo por base os autores da ciência psicodélica. A igreja é vinculada a um instituto científico com cursos, workshops, aulas e pesquisa e a outro instituto dedicado ao clínico e terapêutico. A IDMT considera a religião como um meio e não um fim, e reitera que conhecer a Deus é uma questão de miligramas, para além da questão da fé.

Unindo as descrições dos rituais pós-modernos de jurema, seus participantes são buscadores que procuram conhecer a jurema para várias finalidades místicas e de cura. E especificamente cura para estados mórbidos tais como as manifestações da depressão, ansiedade, comportamentos compulsivos, ou seja,

\footnotetext{
${ }^{13}$ Embora a ação do hipérico como inibidor de monoaminoxidase ainda não esteja comprovada.

${ }^{14}$ Mistura de ervas com cristais de DMT extraídos de entrecascas de juremas.

${ }^{15}$ Perspectiva antiproibicionista de cuidado ao usuário de drogas, que exige ação individualizada, com foco no sujeito (Passos \& Souza, 2011).

${ }^{16}$ Set vem de mindset e representa o espaço pessoal e substância utilizada, enquanto setting se refere ao espaço físico e social da vivência (Zinberg, 1984)
} 
doenças típicas da vida urbana atual e para as quais as possibilidades terapêuticas da modernidade cientificista não são consideradas suficientemente satisfatórias segundo esses novos sujeitos religiosos. Lembrando que a noção de cura operada certos em contextos espirituais ou religiosos tem um caráter processual interminável pelo qual as pessoas vão adicionando novos significados para a vida e o bem-estar, transformando o sentido de ser uma pessoa saudável e promovendo transformações nos estados existenciais (Csordas, 2016).

As religiosidades enteogênicas da jurema, em particular, apresentam forte centralidade no afeto, mas tomam como ponto zero de propulsão um direcionamento ao êxtase. $\mathrm{O}$ arrefecimento das instituições religiosas e a autonomia do sujeito em articular a sua própria religiosidade livre de vínculos e fidelidades, provocam a proliferação de opções religiosas sem que necessariamente essa proliferação surja como novas instituições, e sim de outras formas (Van der Veer, 2009). Como muitos estudiosos têm argumentado, a religião como categoria universal é uma construção moderna com uma genealogia no deísmo universalista e na expansão europeia dos séculos XVI e XVII (Asad, 1993). Um dos aspectos interessantes de atores vinculados a religiosidades de sociedades atuais é que eles combinam atitudes radicais contra a igreja, socialismo anti-establishment e livrepensamento com experimentação espiritual (Van der Veer, 2009).

De fato, diante dos contextos globalizados, essas novas religiosidades são envolvidas em redes de comunicação ${ }^{17}$ permitindo construir, como já exploraram (Silva \& Grünewald, 2019), "perspectivas globais de atuação sob um suposto fundo de preocupações comuns aos sujeitos que delas participam" (Silva \& Grünewald, 2019, p. 200) e as quais emergem a partir de hibridizações ou rearranjos criativos de práticas espirituais provenientes de todos os cantos do mundo e que se configuram histórica ou processualmente a partir da negociação contínua entre "formas diversas de expressão do sagrado ou o que se costuma entender por 'experiência religiosa"".

Steil e Toniol (2013) já consideraram limites analíticos em torno do conceito de religião quando nos deparamos com distintos regimes de crer por meio dos quais um número muito significativo de pessoas expressam suas crenças ou espiritualidades. Essas geralmente não se vinculam a instituições religiosas como mediadoras das suas experiências com o sagrado. Nessa direção, nota-se maior

\footnotetext{
${ }^{17}$ Léo Neto e Grünewald (2012) estabeleceram a noção de rede comunicativa, sinalizando para os fluxos culturais que conformam cartografias simbólicas em contextos rituais multiétnicos (plurais). Já Steil e Toniol (2013) indicam a ideia de "rede" como uma possível chave de compreensão da religião na contemporaneidade.
} 
autonomia dos sujeitos religiosos que buscam preferencialmente centrar "a experiência religiosa na sua subjetividade" (Steil \& Toniol, 2013, p. 13).

Roberts (2013) argumenta que há uma transição da religião baseada em textos para a religião baseada na experiência. A mudança traz uma ampla e profunda transformação no campo, indo de ritos, comportamentos e atividades religiosas, passando por textos religiosos até atualmente estarmos vivendo uma era da experiência religiosa primária. Para ele, os enteógenos democratizam o acesso à experiência religiosa primária. Enquanto na antiga perspectiva religiosa a rota para o conhecimento espiritual viria de leituras e estudos (cognição) - bem como o conhecimento adviria de crenças, doutrinas e dogmas, ancorado na teologia e filosofia -, a nova perspectiva religiosa trilha através da experiência mística (consciência unitiva), por meio da qual o conhecimento espiritual emerge sem mediação (pois advém do contato direto com o divino) e se ancora na biologia e psicologia.

$\mathrm{Na}$ experiência religiosa primária ${ }^{18}$ as crenças se relacionam aos significados com base nos questionamentos de seus adeptos e os rituais são recriados e reelaborados (e recelebrados), tendo por base ética a expressão da unidade, amor e gratidão na ação social responsável. Não que a religião se reduza à experiência mística, porém esta contribui notavelmente, já que uma única experiência espiritual pode contribuir para uma vida espiritual (Roberts, 2013).

Strassman (2014), ao iniciar os estudos com DMT, esperava encontrar estados místicos unificativos de iluminação, livres de conteúdo, com dissolução do ego e fusão a uma fonte divina. Concluiu que não é o cérebro que cria Deus (modelo neuroteológico), mas ele propõe que o cérebro capta Deus, ou seja, o sistema nervoso é um registrador da divindade (modelo teoneurológico). A cura com psicodélicos, na medida em que eles suscitam uma experiência espiritual, propões que agentes externos que agora têm acesso à matriz cérebro-mente-corpo beneficiam os indivíduos. A morte de células cancerígenas, alívio de problemas mentais, cessação do abuso de drogas são as manifestações objetivas do funcionamento de forças invisíveis que modificam processos biológicos e psicológicos (Strassman, 2014). Esta é uma forma recente de articular o pensamento voltado ao religioso que é característico desses juremeiros pós-modernos.

Por fim, para Magnani (1999) essas novas religiosidades - das quais as relativas à jurema pós-moderna aqui mencionada - fazem parte de um "circuito

\footnotetext{
${ }^{18}$ Também chamada de estado de consciência unitivo, experiência mística, experiência de pico, intensa experiência de conversão ou unidade sagrada (Roberts, 2013, pp. 63-64).
} 
neo-esotérico" e formam uma rede não contígua com espaços para cursos, terapias, treinamentos, rituais, venda de produtos e pontos de encontro nos quais circulam os mais variados sistemas.

A partir da recorrência desses novos grupos religiosos é possível identificar a presença de um estilo de vida mais amplo que inclui, como um dos fatores de desenvolvimento das potencialidades pessoais e autoconhecimento, a busca por novas formas de espiritualidade e também de religiosidade (Magnani, 1999). Por fim, como sugerido por (Grünewald, 2008), mais do que tentar classificar essas novas religiosidades da jurema, é preciso estar atento ao que fazem estes novos sujeitos sociais.

De modo geral, no Brasil o conhecimento de navegação mental propiciado pela jurema se converte em religiosidade a partir das bricolagens pautadas nas juremas tradicionais nativas, uma forma de Religiosidade Psiconáutica Enteogênica da Jurema. Esses juremeiros se unem tanto em grupos independentes, mas também em institutos espirituais e organizações religiosas a fim de buscarem os efeitos espirituais da jurema. Ao mesmo tempo em que situam e delineiam seus rituais a partir de tradições religiosas, esotéricas e filosóficas conhecidas, estes sujeitos pós-modernos ampliam o campo místico simbólico da jurema com enxertos de configurações e performances próprios de cada casa.

\section{CONSIDERAÇÕES FINAIS}

Este artigo se propôs a avançar estudos sobre as religiosidades juremeiras brasileiras ao trazer informações acerca de novos usos relativos a um psiconautismo religioso que, embora quantitativamente exíguo, se apresenta com bastante vigor entre seus adeptos (Grünewald, 2005a, 2008, 2018, 2020; Grünewald \& Savoldi, 2019). Como visto ao longo do artigo, religiosidades com juremas existem desde épocas desconhecidas, mas que somente a partir da presença colonial é que tivemos as primeiras informações, especialmente em função da perseguição aos cultos indígenas e depois aos catimbozeiros. Ao olhar para as religiosidades fundadas na jurema, apesar de rupturas, dissidências e outros processos de clivagens religiosas, encontramos também continuidades e realinhamentos que produziram, de várias formas, por diversos motivos e por meio de processos particulares, um leque de religiosidades juremeiras na contemporaneidade.

O termo religiosidade como extensão na qual o indivíduo acredita, segue e pratica uma religião, apesar de ser muitas vezes considerada de significação sobreposta à espiritualidade, difere deste à medida que a espiritualidade não se limita a alguns tipos de crenças ou práticas (Fleck et al., 1999). Como pensamos, 
devemos descartar "sentidos construídos a priori sobre o sagrado" (Grünewald, 2005a) e tentar entrar na perspectiva e no universo cognitivo daqueles que vivenciam experiências específicas e perceber o sagrado e a religiosidade a partir de seus posicionamentos espirituais - mesmo que privatizados, não institucionalizados, mas nem por isso, menos legítimos.

Além disso, qualquer tentativa de folclorizar e reduzir a jurema como uma perspectiva museológica de uma tradição indígena degradada pressupõe uma concepção linear de tempo não correspondente aos dados (Grünewald \& Savoldi, 2019). Com a jurema, há, consequentemente, uma variedade grande de formas de compor a bebida e seus rituais desde sua utilização indígena, passando pelos catimbós, jurema-umbanda e alcançando os usos pós-modernos, das religiosidades psiconáuticas. O que se assinala atualmente, nesse sentido, é um conjunto de processos de revigoramento das culturas específicas dos povos tradicionais. Afinal, desde a chegada do evangelizador colonial em terras brasileiras registramos a falácia de se tentar entender as religiosidades nativas a partir da perspectiva cristã de fé e crença (Pompa, 2003).

Até que ponto as experiências místicas dos grupos tradicionais são fruto de alterações de consciência provocadas prioritariamente pela ingestão de DMT isso não se sabe. Já os neo-juremeiros pós-modernos, baseados na religiosidade ayahuasqueira e holismos, requerem os efeitos enteogênicos evidenciado pela DMT, visto as múltiplas perspectivas que se fundem em torno das "experiências místicas" provocadas pela sua utilização (Grünewald, 2008).

Considerando que todas as juremas - aqui separadas esquematicamente em tradicionais e pós-moderna - conduzem ao sagrado, temos que a jurema é um enteógeno de um ou outro modo: seja em incorporações, visões, percepções etc. No Brasil, entre rupturas e continuidades, todas se encaminham para religiosidades baseadas em "regimes de crer" (Steil \& Toniol, 2013) por meio dos quais seus vários sujeitos buscam o contato com mundos sobrenaturais e expressem suas espiritualidades sem precisar contar necessariamente com instituições religiosas como mediadoras das suas experiências com o sagrado.

Tais experiências não devem ser desligitimadas quando saímos do universo dos juremeiros tradicionais e entramos no mundo psiconáutico, pois a religiosidade enteogênica da juremahuasca é tão legítima e autência quanto as tradicionais. Deuses, espíritos, arquétipos, energias, dimensões etc. são acessados pelos sujeitos da jurema que - cada qual navegando ao seu modo e a partir do cosmos que a eles se apresentam - têm em comum uma construção de (parte de) sua espiritualidade vinculada a esse elemento da natureza - a Jurema - que é por todos eles revestida de 
sacralidade. Do mesmo modo que buscadores de conhecimentos metafísicos sempre existiram desde épocas pré-coloniais, fazendo bricolagens exotéricas e realinhando místérios esotéricos, esses juremeiros pós-modernos se unem tanto em grupos independentes, mas também em institutos espirituais e organizações religiosas, a fim de buscarem os efeitos espirituais da jurema com seus corações e mentes abertas às possibilidades do maravilhoso.

\section{REFERÊNCIAS}

Albuquerque, M. A. de S. (2002). Destreza e sensibilidade: os vários sujeitos da Jurema (as práticas rituais e os diversos usos de um enteógeno nordestino). (Monografia de bacharelado, Universidade Federal de Campina Grande].

Albuquerque, U. P. (2002). A Jurema nas Práticas dos Descendentes Culturais do Africano no Brasil. In C. N. da Mota \& U. P. Albuquerque (eds.), As muitas faces da Jurema: de espécie botânica à divindade afro-indígena (pp. 171-189). Bagaço.

Amaral, L. (2000). Carnaval da Alma: comunidade, essência e sincretismo na Nova Era. Vozes.

Asad, T. (1993) Genealogies of religion: discipline and reasons of power in Christianity and Islam. The Johns Hopkins University Press.

Bairrão, J. F. M. H. (2003). Raízes da Jurema. Psicologia USP, 14(1), 157-184. https://doi.org/10.1590/S0103-65642003000100009

Barker, S. A., McIlhenny, E. H., \& Strassman, R. (2012). A critical review of reports of endogenous psychedelic N, N-dimethyltryptamines in humans: 1955-2010. Drug Testing and Analysis, 4(7-8), 617-635. doi:10.1002/dta.422

Barros, O. M. d. (2011). Terreiros Campinenses: Tradição e diversidade [Tese de doutorado, Universidade Federal de Campina Grande]. Repositório de Teses e Dissertações da UFCG. http://dspace.sti.ufcg.edu.br:8080/xmlui/bitstream/handle/riufcg/2322/OFÉLIA MARIA DE BARROS - TESE PPGCS 2011..pdf

Bastide, R. (1945). Imagens do Nordeste místico em branco e preto. "Seção de livros" da emprêsa gráfica "O Cruzeiro" S.A.

Batista, M. R. R. (1992). De Caboclos da Assunção a Índios Truká: estudo sobre a emergência da identidade étnica Truká [Dissertação de mestrado, Universidde Federal do Rio de Janeiro]. Museu Nacional; UFRJ.

Bloom, J. D. (2009). Dictionary of Hallucinations. Springer. https://doi.org/10.1007/978-1-44191223-7_14

Brandão, M. d. C., \& Rios, L. F. (2001). O Catimbó-Jurma do Recife. In R. Prandi (ed.), Encantaria brasileira, o livro dos Mestres, Caboclos e Encantados (pp. 160-181). Pallas.

Carlini, A. L. R. da S. (1993). Cachimbo e maracá: o catimbo da Missão (1938). Centro Cultural.

Camargo, M. T. L. de A. (2014). As plantas medicinais e o sagrado: A etnofarmacobotânica em uma revisão historiográfica da medicina popular no Brasil. Ícone.

Carreras, L., \& Alonso, M. G. (1967). Separation of the major alkaloids of Peganum harmala by high voltage ionophoresis. Journal of Chromatography A, 29(2), 388-390. https://doi.org/10.1016/S0021-9673(00)92682-7

Cascudo, L. da C. (1937). Notas sobre o catimbó. Novos Estudos Afro-Brasileiros, (2), 75-129. 
Cascudo, L. da C. (1978). Literatura oral no Brasil de Luís da Câmara Cascudo. Livraria J. Olympio.

Csordas, T. J. (2016). Imaginal performance and memory in ritual healing. In C. Laderman \& M. Roseman (eds.), The performance of healing (pp. 91-114). Routledge. https://doi.org/10.4324/9781315538860-4

da Mota, C. N. (1987). As Jurema told us: Kariri-Shoko and Shoko mode of utilization of medicinal plants in the context of modern Northeastern Brazil [Tese de doutorado, University of Texas]. University of Texas at Austin.

da Mota, C. N. (2005). Jurema e identidades: um ensaio sobre a diáspora de uma planta. In B. C. Labate \& S. L. Goulart (eds.), O uso ritual das plantas de poder (pp. 219-239). Mercado das Letras.

da Mota, C. N., \& Barros, J. P. d. (2002). O Complexo da Jurema: representações e drama social negro-indígena. In: C. N. da Mota \& U. P. Albuquerque (eds.), As muitas faces da Jurema: de espécie botânica à divindade afro-indígena (pp. 19-60). Bagaço.

de Lima, O. G. (1944). Nigerina, novo alcalóide isolado da "Jurema preta" (Mimosa hostilis). Anais da Sociedade de Biologia de Pernambuco, 5(1), 24.

de Oliveira, C. E. (1942). O ossuário da "Gruta-do-Padre", em Itaparica, e algumas notícias sobre remanescentes indigenas do Nordeste. Imprensa Nacional.

de Salles, S. G. (2004). À Sombra da Jurema: um estudo sobre a tradição dos Mestres Juremeiros na Umbanda de Alhandra-PB [Dissertação de mestrado, Universidade Federal do Rio Grande do Norte].

Fernandes, G. (1938). O Folclore mágico do Nordeste: usos, costumes crenças \& ofícios mágicos das populações nordestinas. Civilização Brasileira.

Fleck, M. P. A., Leal, O. F., Louzada, S., Xavier, M., Chachamovich, E., Vieira, G., Pinzon, V. (1999). Desenvolvimento da versão em português do instrumento de avaliação de qualidade de vida da OMS (WHOQOL-100). Revista Brasileira de Psiquiatria, 21(1), 19-28. https://doi.org/10.1590/S1516-44461999000100006

Grünewald, R. de A. (1993). Regime de índio e faccionalismo: os Atikum da Serra do Umã [Dissertação de mestrado, Universidade Federal do Rio de Janeiro].

Grünewald, R. de A. (2002). A Jurema no 'Regime de Índio': o caso Atikum. In C. N. da Mota \& U. P. Albuquerque (eds.), As muitas faces da Jurema: de espécie botânica à divindade afro-indigena (pp. 97-124). Bagaço.

Grünewald, R. de A. (2005a). Sujeitos da jurema e o resgate da ciencia do indio. In B. C. Labate \& S. L. Goulart (eds.), O uso ritual das plantas de poder (pp. 239-278). Mercado de Letras.

Grünewald, R. de A. (2005b). Toré: regime encantado do índio do nordeste Fundação Joaquim Nabuco; Massangana.

Grünewald, R. de A. (2008). Jurema e novas religiosidades metropolitanas. In L. S. de Almeida \& A. H. L. da Silva (eds.), Índios do Nordeste X: etnia, política e história (pp. 11-36). EDUFAL.

Grünewald, R. de A. (2018). Nas Trilhas da Jurema. Religião e Sociedade, 38(1), 110-135. https://doi.org/10.1590/0100-85872018v38n1cap05

Grünewald, R. de A. (2020). Jurema. Mercado de Letras.

Grünewald, R. de A., \& Savoldi, R. (2019). Contextos e usos da jurema. In B. C. Labate \& S. L. Goulart (eds.), O Uso de Plantas Psicoativas nas Américas (pp. 327-345). Gramma. 
Hohenthal, W. D., Jr. (1960). As Tribos Indígenas do Médio e Baixo São Francisco (Vol. 12). Nova Série.

Jünger, E. (1970). Psychonauten. Annäherungen: Drogen und Rausch. Ernst Klett.

L'Odò, A. L. O. (2017). Juremologia: Uma busca etnográfica para sistematização de princípios da cosmovisão da Jurema Sagrada [Dissertação de mestrado, Universidade Católica de Pernambuco]. Biblioteca Digital de Teses e Dissertações, Universidade Católica de Pernambuco. http://tede2.unicap.br:8080/bitstream/tede/933/2/Ok_alexandre_lomi_lodo.pdf

Labate, B. C. (2000). A reinvenção do uso da ayahuasca nos centros urbanos [Dissertação de mestrado, Universidade Estadual de Campinas].

Léo Neto, N. A., \& Grünewald, R. de A. (2012). Lá no meu reinado eu só como é mel': Dinâmica cosmológica entre os índios Atikum, PE. Tellus, (22), 49-80.

Lima Segundo, F. S. (2015). Cidade da Mestra Jardecilha: memória e tradição de conhecimento da Jurema Sagrada em Alhandra $(P B)$ [Dissertação de mestrado, Universidade Federal da Paraíba]. Repositório Institucional da UFPB. https://repositorio.ufpb.br/jspui/bitstream/tede/7540/5/arquivototal.pdf

Magnani, J. G. C. (1999). O xamanismo urbano e a religiosidade contemporânea. Religião e Sociedade, 20(2), 113-140.

Mata, V. L. (1989). A semente da terra: identidade e conquista territorial por um grupo indigena integrado [Tese de doutorado, Universidade Federal do Rio de Janeiro]. Museu Nacional; UFRJ.

McKenna, D. J., Towers, G. H., \& Abbott, F. (1984). Monoamine oxidase inhibitors in South American hallucinogenic plants: tryptamine and beta-carboline constituents of ayahuasca. Journal of Ethnopharmacology, 10(2), 195-223. https://doi.org/10.1016/03788741(84)90003-5

Motta, R. (1985). Catimbós, xangôs e umbandas na região do Recife. In R. Motta (ed.), Os AfrosBrasileiros. Anais do III Congresso Afrobrasileiro (pp. 109-123). Massangana.

Nascimento, M. T. de S. (1994). O tronco da jurema: Ritual e etnicidade entre os povos indigenas do Nordeste - O caso Kiriri. [Dissertação de mestrado, Universidade Federal da Bahia].

Newcombe, R., \& Johnson, M. (1999). Psychonautics: a model and method for exploring the effects of psychedelic drugs [apresentação de artigo]. Club Health 2000 Conference, Amsterdã.

Oliveira (L'Omi L'Odò), A. A. de S. (2011). Teologia Da Jurema. Existe Alguma? In L. C. L. Marques (ed.), Anais Eletrônicos do V Colóquio de História. Perspectivas Históricas: historiografia, pesquisa e patrimônio (pp. 1083-1106). http://www.unicap.br/coloquiodehistoria/wpcontent/uploads/2013/11/5Col-p.1083-1106.pdf

Ott, J. (2002). Farmahuasca, anahuasca e jurema preta: farmacologia humana da DMT via oral combinada com harmina. In B. C. Labate \& W. S. Araújo (eds.), O uso ritual da ayahuasca (pp. 711-729). Mercado das Letras.

Ott, J. (2011). Psychonautic uses of "Ayahuasca" and its analogues: Panacæa or Outré Entertainment. In H. Jungaberle \& B. C. Labate (eds.), The internationalization of ayahuasca (pp. 105-122). LIT Verlag.

Pacheco de Oliveira, J. (1999). Uma etnologia dos "índios misturados"? Situação colonial, territorialização e fluxos culturais. In J. Pacheco de Oliveira (ed.), A Viagem da Volta. Etnicidade, política e reelaboração cultural no Nordeste indígena (pp.11-39). Contra Capa.

Passos, E. H., \& Souza, T. P. (2011). Redução de danos e saúde pública: construções alternativas à política global de "guerra às drogas". Psicologia \& Sociedade, 23(1), 154-162. https://doi.org/10.1590/S0102-71822011000100017 
Peirano, M. G. (2000). A análise antropológica de rituais (Série Antropologia 270). Universidade de Brasília.

Pinto, E. (1956). Etnologia brasileira:(Fulnio-os últimos Tapuas). Brasiliana.

Pompa, C. (2003). A Religião como Tradução. Missionários, Tupi e Tapuia no Brasil Colonial. EDUSC; ANPOCS.

Roberts, T. B. (2013). The psychedelic future of the mind: How entheogens are enhancing cognition, boosting intelligence, and raising values. Inner Traditions; Bear \& Co.

Rodrigues, R. de O. (2014). Ritual em Tambiah: trajetória, conceitos e reflexões. Revista Brasileira de História das Religiões, 7(20), 187-197.

Ruck, C. A., Bigwood, J., Staples, D., Ott, J., \& Wasson, R. G. (1979). Entheogens. Journal of Psychedelic Drugs, 11(1-2), 145-146. https://doi.org/10.1080/02791072.1979.10472098

Sangirardi, Â. B., Jr. (1983). O índio e as plantas alucinógenas: Alhambra.

Santiago, I. M. F. L. (2008). A Jurema Sagrada da Paraíba. Qualitas Revista Eletrônica, 6(2). http://revista.uepb.edu.br/index.php/qualitas/article/view/122/98

Santos, A. J. B. (2007). Jurema: A Ciência dos Caboclos. Livro Rápido - Elógica.

Silva, C. B. (2000). Índios fortes: aspectos empíricos e interpretativos do xamanismo Kariri-Xocó. In L. S. Almeida (ed.), Índios do Nordeste: temas e problemas (Vol. 2, pp. 315-346). EDUFAL.

Silva, D. V., \& Grünewald, R. de A. (2019). Velhas e Novas Crenças: sobre o encontro de religiosidades em uma vila amazônica. Religião \& Sociedade, 39(1), 198-223. https://doi.org/10.1590/0100-85872019v39n1cap09

Soares, L. E. (1994). Religioso por Natureza: cultura alternativa e misticismo ecológico no Brasil. In. L. E. Soares (ed.). O Rigor da indisciplina: Ensaios de Antropologia Interpretativa (189-212). Relume-Dumará.

Steil, C. A; Toniol, R. (2013). A crise do conceito de Religião e sua Incidência sobre a Antropologia. https://www.researchgate.net/publication/294090350_A_crise_do_conceito_de_religiao_e_s ua_incidencia_sobre_a_antropologia/link/56be357708aeedba05611384/download

Strassman, R. J. (1996). Human psychopharmacology of N,N-dimethyltryptamine. Behavioural Brain Research, 73(1-2), 121-124. https://doi.org/10.1016/0166-4328(96)00081-2

Strassman, R. J. (2014). DMT and the soul of prophecy: A new science of spiritual revelation in the Hebrew Bible. Inner Traditions; Bear \& Co.

Strassman, R. J., Qualls, C. R., Uhlenhuth, E. H., \& Kellner, R. (1994). Dose-response study of $\mathrm{N}, \mathrm{N}$-dimethyltryptamine in humans. II. Subjective effects and preliminary results of a new rating scale. Archives Of General Psychiatry, 51(2), 98-108. https://doi.org/10.1001/archpsyc.1994.03950020022002

Tambiah, S. J. (2017). Form and meaning of magical acts: A point of view. Journal of Ethnographic Theory, 7(3), 451-473. https://doi.org/10.14318/hau7.3.030

Van der Veer, P. (2009). Spirituality in modern society. Social Research: An International Quarterly, 76(4), 1097-1120.

Vandezande, R. (1975). Catimbó: pesquisa exploratória sobre uma forma nordestina de religião mediúnica [Dissertação de mestrado, Universidade Federal de Pernambuco].

Wadsworth, J. E. (2006). Jurema and Batuque: Indians, africans, and the inquisition in colonial northeastern Brazil. History of religions, 46(2), 140-162. https://doi.org/10.1086/511448

Zinberg, N. E. (1984). Drug, set, and setting: The basis for controlled intoxicant use. Yale University Press. 